\title{
The Simulation of Operation Cost in Laparoscopy-Assisted and Laparoscopic Distal Gastrectomy Under the National Health Insurance System in Japan
}

\author{
Yoshiyuki Hoya ${ }^{1}$, Tomoyoshi Okamoto ${ }^{1}$, Norio Mitsumori ${ }^{2}$, Katsuhiko Yanaga ${ }^{2}$ \\ ${ }^{1}$ Department of Surgery, Daisan Hospital, The Jikei University School of Medicine, Tokyo, Japan \\ ${ }^{2}$ Department of Surgery, The Jikei University School of Medicine, Tokyo, Japan
}

Email address:

hoya@jikei.ac.jp (Y. Hoya)

\section{To cite this article:}

Yoshiyuki Hoya, Tomoyoshi Okamoto, Norio Mitsumori, Katsuhiko Yanaga. The Simulation of Operation Cost in Laparoscopy-Assisted and Laparoscopic Distal Gastrectomy Under the National Health Insurance System in Japan. Advances in Surgical Sciences.

Vol. 5, No. 4, 2017, pp. 53-56. doi: 10.11648/j.ass.20170504.13

Received: February 18, 2017; Accepted: June 29, 2017; Published: July 31, 2017

\begin{abstract}
The utility and problems including the socioeconomic aspect of laparoscopy-assisted (LADG) and laparoscopic distal gastrectomy (LDG) for gastric cancer has not been fully evaluated. We compared between open distal gastrectomy (ODG), LADG and LDG, the clinical benefit and quality of life by the reference documents. The problems of operation cost were derived by simulating the material used for each operation with Billroth I (B-I) reconstruction, and calculating the operation fee under the national health insurance system in Japan. The operation time of LADG and LDG was longer than that of ODG. However, the intraoperative blood loss of LADG and LDG was less and the postoperative hospital stay as well as the duration of fasting after LADG and LDG were shorter than those after ODG. The number of excised lymph nodes and the incidence of postoperative complications were comparable between LADG, LDG and ODG. On the other hand, in the national health insurance system, the operation fee of ODG was US\$7187 as compared to US\$8012 for LADG and US\$7962 for LDG. In spite of the US\$825 and US\$775 difference in the operation fee, the use of disposable instruments for LADG and LDG results in the deficit of approximately US\$650 and US\$850 over ODG, respectively. In spite of the medical superiority of LADG and LDG over ODG as less invasive surgery, LADG and LDG in the current Japanese health insurance system are associated with less financial benefit to the hospital as compared to ODG.
\end{abstract}

Keywords: Laparoscopy-Assisted Distal Gastrectomy, Gastric Cancer, Health Insurance, Minimally Invasive Surgery, Cost Benefit

\section{Introduction}

In Japan, national health insurance is mandatory and covers virtually all residents of Japan to offer adequate and equitable medical care. On the other hand, growth of national health care expenditure is a major problem due to financial difficulty and burden confronting the national government. Although most hospitals in Japan are non-profit organizations, financial balance associated with the surgical procedure is an important issue. Generally, the medical superiority of laparoscopy-assisted (LADG) and laparoscopic distal gastrectomy (LDG) over open distal gastrectomy (ODG) has been documented in various reports. Recently, the minimally invasive surgery with laparoscopy for advanced gastric cancer often have been increasingly performed in developed countries [1], and the Japanese social insurance system has changed the payment of LADG and LDG as of April 1, 2006, 2008, 2010, 2012 and 2014. In spite of the frequent changes in insurance payment, the cost of the disposable surgical instruments is yet to be fully covered. In this study, we examined the utility and problems of the LADG and LDG for gastric cancer with special emphasis on the socioeconomic issue.

\section{Subjects and Methods}

We compared between ODG, LADG and LDG the clinical benefit, quality of life, and problems of operation 
cost by the reference documents in which the differences among the procedures were examined in detail. Thirty two reference documents were retrieved by key words "gastric, cancer, laparoscopic and surgery" in PubMed with the following limits activated : Humans, Clinical Trial, Controlled Clinical Trial, Meta-Analysis, Randomized Controlled Trial, Review, English, Core clinical journals and published between January 2004 and December 2013. The following factors were evaluated to assess the clinical benefit and quality of life: operation time, intraoperative blood loss, postoperative hospital stay, duration of fasting after operaton, number of excised lymph nodes and incidence of postoperative complication. The problems of operation cost were derived by simulating the materials used for each operation with Billroth I (B-I) reconstruction (Delta anastomosis was performed in LDG), and by calculating the operation fee under the national health insurance system in Japan.

\section{Results}

According to the reference documents retrieved in this study, the operation time of LADG and LDG was longer than that of ODG. However, the intraoperative blood loss of LADG and LDG was less, and the postoperative hospital stay as well as the duration of fasting after LADG and LDG were shorter than ODG. The number of excised lymph nodes and the incidence of postoperative complications of LADG and LDG have been reported to be comparable with ODG (Table 1) [1] [12]. In this study, the same tendency of the clinical profit and the disadvantage of LADG and LDG was confirmed. On the other hand, operation fee for ODG (basic charge) for gastric cancer was US\$5587, while that of the LADG and LDG was US\$6412, and the additional fee for disposable instruments become progressively are covered by the insurance. Therefore, the operation fee of ODG was US\$7187, US\$8012 for LADG and US\$7962 for LDG (Table 2). Because various disposable operative equipments were required to perform $\mathrm{LADG}$ or $\mathrm{LDG}$ as compared to ODG (Table 3 and 4), the total operation fee of LADG and LDG was US\$825 and US\$775 higher than that of ODG, respectively, while the operation profit decreased by approximately US\$650 and US\$850 under the revised national health insurance system as of April 1, 2014 in Japan (Table 5).

Table 1. Clinical features of laparoscopy-assisted and laparoscopic distal gastrectomy as compared with open distal gastrectomy.

\begin{tabular}{ll}
\hline Operation time & ODG $<$ LADG / LDG \\
Intraoperative blood loss & ODG $>$ LADG / LDG \\
Wound pain & ODG $>$ LADG / LDG \\
Hospitalization days & ODG $>$ LADG / LDG \\
Duration of fasting after operaton & ODG $>$ LADG / LDG \\
Number of excised lymph nodes & ODG $=$ LADG / LDG \\
Incidence of postoperative complication & ODG $=$ LADG / LDG \\
\hline
\end{tabular}

Cited references [1] [12]

Table 2. Operation fee of distal gastrectomy for gastric cancer as of April 2014.

\begin{tabular}{llll}
\hline & Open & Laparoscopy-assisted & Laparoscopic \\
\hline Operation fee (basic charge) & $5,587^{*}$ & 6,412 \\
Additional fee : & & & \\
Circular stapler & $550(\times 1)$ & $550(\times 1)$ \\
Linear stapler & $250(\times 3)$ & $250(\times 3)$ & 300 \\
Hemostatic device** & 300 & 8,012 & 300 \\
Total operation fee : & 7,187 & 7,962 \\
\hline
\end{tabular}

*\$:USD (1\$:100 yen) ${ }^{* *}$ Ultrasonic shears and Vessel sealing instrument

Table 3. Disposable instruments required for open distal gastrectomy, and laparoscopy-assisted or laparoscopic distal gastrectomy: standard price when Billroth I is performed (Company A).

\begin{tabular}{lll}
\hline & Open & Laparoscopy-assisted \\
\hline Linear Stapler: & $370^{*}$ & \\
Linear Stapler, reload: & 280 & 740 \\
Circular Stapler: & 740 & 250 \\
Endoscopic Linear Stapler: & & $360 \times 3$ \\
Endoscopic Linear Stapler, reload 60: & & 250 \\
Endoscopic Linear Stapler, reload 45: & & $360 \times 4$ \\
Organ retriever: & & 200 \\
Wound Protecter: & & 150 \\
Trocar for laparoscopy: & & $138 \times 2$ \\
Trocar 12mm: & & $98 \times 2$ \\
Trocar 5mm: & 480 & 480 \\
Ultrasonic shears: & 1,870 & 300 \\
Total cost: & & 3,372 \\
\hline
\end{tabular}

* \$:USD (1\$:100 yen) 
Table 4. Disposable instruments required for open distal gastrectomy, and laparoscopy-assisted or laparoscopic distal gastrectomy: standard price when Billroth I is performed (Company B).

\begin{tabular}{llll}
\hline & Open & Laparoscopy-assisted & Laparoscopic \\
\hline Linear Stapler: & 310 & & \\
Linear Stapler, reload: & 250 & 570 & 235 \\
Circular Stapler: & 570 & 235 & $290 \times 4$ \\
Endoscopic Linear Stapler: & & $290 \times 3$ & 280 \\
Endoscopic Linear Stapler, reload 60: & & & 200 \\
Endoscopic Linear Stapler, reload 45: & & & 200 \\
Organ retriever: & & 200 & 143 \\
Wound Protecter: & & 143 & $155 \times 2$ \\
Trocar for laparoscopy: & & $155 \times 2$ & $125 \times 2$ \\
Trocar 12mm: & 830 & $125 \times 2$ & 830 \\
Trocar 5mm: & 1,960 & 830 & 3,608 \\
Ultrasonic shears: & & 3,408 & \\
Total cost: & & \\
\hline
\end{tabular}

*\$:USD (1\$:100 yen)

Table 5. Loss for the hospital per case of laparoscopy-assisted and laparoscopic distal gastrectomy .

\begin{tabular}{lccc}
\hline & Open & Laparoscopy-assisted & Laparoscopic \\
\hline Company A: & & & \\
Total operation fee & 7,187 & 8,012 & 7,962 \\
Disposable instruments price & 1,870 & 3,372 & 3,482 \\
Hospital profit & 5,317 & 4,640 & 4,480 \\
Company B: & & & 7,962 \\
Total operation fee & 7,187 & 8,012 & 3,608 \\
Disposable instruments price & 1,960 & 3,408 & 4,354 \\
Hospital profit & 5,227 & 4,604 & \\
\hline
\end{tabular}

*\$:USD (1\$:100 yen)

\section{Discussion}

LADG and LDG are more useful than ODG as minimally invasive surgery by shortening hospitalization and by reducing medical care cost [10] [13]. However, the cost of the disposable surgical instruments is not fully covered by the health insurance in Japan. The hospital cannot charge medical expenses exceeding the limit set by the national health insurance to the patient. Therefore, the hospital has to cover the operation cost exceeding the ceiling set by the national health insurance payment. Moreover, when the anastomosis is performed in the abdominal cavity in LDG, the operation wound becomes small as compared with LADG. However, because many disposable instruments which generally exceeds additional fee are used in LDG, the hospital profit is lower than LADG.

The cost reduction strategy for LADG and LDG under the national health insurance system in Japan includes the use of inexpensive disposable or reusable instruments, limitation of the use of the energy device to only one, and reduction of the use of non-refundable disposable instruments [14] [16] and the choice of B-I instead of R-Y which needs more disposable instruments for the reconstruction.

At present, the operation fee has been excluded from the inclusive payment on the new system called the Diagnosis Procedure Combination (DPC) [17] that begun in 2003 at many public and private university hospitals, a public cancer center, and a public cardiac care hospitals. Although, the deficit of the hospital has been reduced by the revision of the insurance system, the hospitals have defrayed the cost of disposable operation equipments that exceeds the health insurance coverage.

In the current study, we focused on operation costs and discussed financial benefit to the hospital. However, it is also necessary to examine the effect that the difference on treatment outcome such as the length of hospital stay gives to financial benefit in DPC, and the medical economy should be discussed generally only about operation costs.

\section{Conclusion}

In conclusion, $\mathrm{LADG}$ and LDG are superior to ODG as less invasive surgery however which is associated with decreased hospital profit under the current national health insurance system in Japan.

\section{References}

[1] Otsuka K, Murakami M, Aoki T, Tajima Y, Kaetsu T, Lefor AT. Minimally invasive treatment of stomach cancer. Cancer J 2005; 11: $18-25$.

[2] Zeng YK, Yang ZL, Peng JS, Lin HS, Cai L. Laparoscopy-assisted versus open distal gastrectomy for early gastric cancer: evidence from randomized and nonrandomized clinical trials. Ann Surg 2012; 256: 39-52.

[3] Viñuela EF, Gonen M, Brennan MF, Coit DG, Strong VE. Laparoscopic versus open distal gastrectomy for gastric cancer: a meta-analysis of randomized controlled trials and high-quality nonrandomized studies. Ann Surg 2012; 255: 446-56. 
[4] Kodera Y, Fujiwara M, Ohashi N, Nakayama G, Koike M, Morita S, Nakao A. Laparoscopic surgery for gastric cancer: a collective review with meta-analysis of randomized trials. J Am Coll Surg 2010; 211: 677-86.

[5] Kim HH, Hyung WJ, Cho GS, Kim MC, Han SU, Kim W, Ryu SW, Lee HJ, Song KY. Morbidity and mortality of laparoscopic gastrectomy versus open gastrectomy for gastric cancer: an interim report--a phase III multicenter, prospective, randomized Trial (KLASS Trial). Ann Surg 2010; 251: 417-20.

[6] Cho GS, Kim W, Kim HH, Ryu SW, Kim MC, Ryu SY. Multicentre study of the safety of laparoscopic subtotal gastrectomy for gastric cancer in the elderly. Br J Surg 2009; 96 : 1437-42.

[7] Kim YW, Baik YH, Yun YH, Nam BH, Kim DH, Choi IJ, Bae JM. Improved quality of life outcomes after laparoscopy-assisted distal gastrectomy for early gastric cancer: results of a prospective randomized clinical trial. Ann Surg 2008; 248: 721-7.

[8] Kitano S, Shiraishi N, Uyama I, Sugihara K, Tanigawa N; Japanese Laparoscopic Surgery Study Group. A multicenter study on oncologic outcome of laparoscopic gastrectomy for early cancer in Japan. Ann Surg 2007; 245: 68-72.

[9] Huscher CG, Mingoli A, Sgarzini G, Sansonetti A, Di Paola M, Recher A, Ponzano C. Laparoscopic versus open subtotal gastrectomy for distal gastric cancer: five-year results of a randomized prospective trial. Ann Surg 2005; 241: 232-7.

[10] Migoh S MD, Hasuda K MD, Nakashima K MD, Anai H MD. The benefit of laparoscopy-assisted distal gastrectomy compared with conventional open distal gastrectomy: a case-matched control study. Hepatogastroenterology 2003; 50: 2251-4.

[11] Shimizu S, Uchiyama A, Mizumoto K, Morisaki T, Nakamura $\mathrm{K}$, Shimura $\mathrm{H}$, et al. Laparoscopically assisted distal gastrectomy for early gastric cancer: is it superior to open surgery? Surg Endosc 2000; 14: 27-31.

[12] Yano H, Monden T, Kinuta M, Nakano Y, Tono T, Matsui S, et al. The usefulness of laparoscopy-assisted distal gastrectomy in comparison with that of open distal gastrectomy for early gastric cancer. Gastric Cancer 2001; 4: 93-7.

[13] Mochiki E, Nakabayashi T, Kamimura H, Haga N, Asao T, Kuwano H. Gastrointestinal recovery and outcome after laparoscopy-assisted versus conventional open distal gastrectomy for early gastric cancer. World J Surg 2002; 26: 1145-9.

[14] Adachi Y, Shiraishi N, Shiromizu A, Bandoh T, Aramaki M, Kitano S. Laparoscopy-assisted Billroth I gastrectomy compared with conventional open gastrectomy. Arch Surg 2000; 135: 806-10.

[15] Kasai Y, Fujiwara M, Nakao A. Laparoscopic distal gastrectomy for early gastric cancer. Gastroenterology 2001; 33: 369-75.

[16] Adachi Y, Shiraishi N, Ikebe K, Aramaki M, Bandoh T, Kitano S. Evaluation of the cost for laparoscopic-assisted Billroth I gastrectomy. Surg Endosc 2001; 15: 932-6.

[17] Ishikawa K, Yamamoto M, Kishi DT, Nabeshima T. New prospective payment system in Japan. Am J Health Syst Pharm 2005; 62: 1617-9. 